\title{
An assessment of selected immune parameters of patients with Hodgkin's disease
}

\author{
ANDRZEJ KOŁTAN ${ }^{1}$, SYLWIA KOŁTAN ${ }^{1}$, ROBERT DĘBSKI ${ }^{1}$, ELŻBIETA GRZEŚKK ${ }^{1}$, \\ MARIUSZ WYSOCKI ${ }^{1}$ and GRZEGORZ GRZEŚK ${ }^{2}$ \\ Departments of ${ }^{1}$ Pediatrics, Hematology and Oncology and ${ }^{2}$ Pharmacology and Therapeutics, \\ Collegium Medicum in Bydgoszcz, Nicolaus Copernicus University in Toruń, Bydgoszcz 85-094, Poland
}

Received May 20, 2014; Accepted September 5, 2014

DOI: $10.3892 / \mathrm{mco} .2014 .421$

\begin{abstract}
Malignancy and oncologic treatment lead to various secondary immune disorders. In particular, little is known regarding immune reconstitution following cancer therapy. Lymphocytes, their subpopulations and immunoglobulin serum concentrations were assessed in patients with Hodgkin's disease at diagnosis (group I, 26 patients), cessation of therapy (group II, 21 patients) and 2 years after treatment (group III, 18 patients). Absolute lymphocyte count was significantly decreased in group II only (15/21 vs. 6/26 and $0 / 18$ patients). In group I, the absolute count of the following subsets were decreased: Cluster of differentiation $19^{+}\left(\mathrm{CD} 19^{+}\right)$ (18/26 patients), $\mathrm{CD}^{+}(13 / 26), \mathrm{CD}^{+} \mathrm{CD}^{+}(11 / 26)$ and $\mathrm{CD}^{+} \mathrm{CD}^{+}(7 / 26)$. In group II, the reduction of $\mathrm{CD} 19^{+}, \mathrm{CD}^{+}$ and $\mathrm{CD}^{+}{ }^{+} \mathrm{CD} 4^{+}$cell counts was evident $(12 / 21,16 / 21$ and $19 / 21$ patients, respectively), with the $\mathrm{CD}^{+} \mathrm{CD}^{+} / \mathrm{CD}^{+} \mathrm{CD}^{+}$ ratio distinctly lowered in the majority of patients (16/21). Similar changes in the percentages of lymphocyte subsets were observed. In the majority of patients in group III, the percentage of lymphocyte subsets were normal, but absolute lymphocyte counts were elevated $\left(\mathrm{CD} 19^{+}\right.$in $11 / 18, \mathrm{CD}^{+}$in $12 / 18, \mathrm{CD}^{+} \mathrm{CD}^{+}$in $13 / 18$ and $\mathrm{CD}^{+} \mathrm{CD}^{+}$in $11 / 18$ patients). In half the patients at diagnosis, immunoglobulin $\mathrm{G}(\mathrm{IgG})$ was significantly elevated. In conclusion, disorders assessed in the percentage distribution and individual subpopulations of lymphocytes was applicable mainly to patients at the time of the diagnosis and shortly following completion of treatment. The analysis of time-distant consequences showed disorders only in the content of the percentage of $\mathrm{CD} 4^{+}$memory cells. The concentration of IgG at the time of diagnosis was
\end{abstract}

Correspondence to: Dr Andrzej Kołtan or Dr Elżbieta Grześk, Department of Pediatrics, Hematology and Oncology, Collegium Medicum in Bydgoszcz, Nicolaus Copernicus University in Torun, 9 Sklodowskiej-Curie Street, Bydgoszcz 85-094, Poland

E-mail: akoltan@by.home.pl

E-mail: ellag@cm.umk.pl

Key words: Hodgkin's disease, lymphocyte subpopulations, immunoglobulin levels significantly elevated in half the patients, which is possibly associated with the pathogenesis of the disease. The treatment does not appear to noticeably affect the production of $\operatorname{IgG}, \operatorname{Ig} \mathrm{A}$ and $\operatorname{IgM}$.

\section{Introduction}

Hodgkin's disease (HD) belongs to a group of illnesses in which there is a serious impairment of the immune system over the course of the disease (1). However, knowledge regarding the influence of the disease itself and the treatment applied for the individual functions of the immune system appears to be incomplete. There are no cases in which individual immunological parameters have been evaluated periodically with the same patients (at the time of the diagnosis, at the end of treatment and after several years). An evaluation of these parameters is particularly important as $90 \%$ of patients have long-lasting remissions and it is necessary to take action to ensure their best possible quality of life. Identification of serious, temporary and persistent immune disorders may aid the recognition of the risk group in developing severe infections and to take preventive steps against such complications. This group of patients may be at risk of secondary cancer and thus special oncologic monitoring is recommended (1).

The aim of the present study was the evaluation of: i) The absolute number of lymphocytes, percentage and absolute count of their subpopulations [cluster of differentiation $19^{+}\left(\mathrm{CD} 19^{+}\right)$, $\mathrm{CD}^{+}, \mathrm{CD}^{+}{ }^{+} \mathrm{CD} 4^{+}, \mathrm{CD}^{+}{ }^{+} \mathrm{CD} 8^{+}$and $\left.\mathrm{CD} 3-\left(\mathrm{CD} 16^{+} \mathrm{CD} 56^{+}\right)\right]$in correspondence to the normal range. ii) Serum concentrations of immunoglobulins (Ig) G, IgA and IgM in patients with HD at the time of the diagnosis (group I), 10-14 days after completion of their treatment (group II) and after at least 2 years from the end of oncologic treatment (group III). iii) Additionally, in group III the contents of naive cells (CD45RA) and memory cells $(\mathrm{CD} 45 \mathrm{RO})$ in the $\mathrm{CD}^{+} \mathrm{CD}^{+}$and $\mathrm{CD}^{+} \mathrm{CD}^{+}$population were assessed.

\section{Patients and methods}

Patient characteristics. The study included 26 patients with diagnosed HD treated in the Department of Pediatrics, Hematology and Oncology of Collegium Medicum (Bydgoszcz, Poland), in accordance with the HD-97 protocol issued by 
Table I. Characteristics of the patient groups.

\begin{tabular}{|c|c|c|c|}
\hline Characteristics & Group I (n=26) & Group II (n=23) & Group III $(n=22)$ \\
\hline \multicolumn{4}{|c|}{ Age at the time of examination, years } \\
\hline Mean & 14.1 & 15.8 & 18 \\
\hline Median & 15.8 & 17.0 & 19.3 \\
\hline Range & $3.0-18.8$ & $5.6-19.2$ & $6.9-24.8$ \\
\hline \multicolumn{4}{|l|}{ Gender, n (\%) } \\
\hline Female & $16(61.5)$ & $15(65.2)$ & $15(68.2)$ \\
\hline Male & $10(38.5)$ & $8(34.8)$ & $7(31.8)$ \\
\hline \multicolumn{4}{|c|}{ Clinical stage, n (\%) } \\
\hline IA & $1(3.8)$ & $0(0.0)$ & $2(9.1)$ \\
\hline IB & $1(3.8)$ & $1(4.3)$ & $0(0.0)$ \\
\hline IIA & $8(30.8)$ & $6(26.1)$ & $8(36.4)$ \\
\hline IIB & $8(30.8)$ & $8(34.8)$ & $6(27.3)$ \\
\hline IIIA & $3(11.5)$ & $3(13.0)$ & $3(13.6)$ \\
\hline IIIB & $2(7.7)$ & $1(4.3)$ & $2(9.1)$ \\
\hline IVA & $0(0.0)$ & $0(0.0)$ & $0(0.0)$ \\
\hline IVB & $3(11.5)$ & $4(17.4)$ & $1(4.5)$ \\
\hline \multicolumn{4}{|c|}{ Therapeutic group acccording to HD-97, n (\%) } \\
\hline I & $2(7.7)$ & $1(4.3)$ & $2(9.1)$ \\
\hline II & $8(30.8)$ & $6(26.1)$ & $8(36.4)$ \\
\hline III & $11(42.3)$ & $11(47.8)$ & $9(40.9)$ \\
\hline IV & $5(19.2)$ & $5(21.7)$ & $3(13.6)$ \\
\hline \multicolumn{4}{|c|}{ Mediastinal radiotherapy, $\mathrm{n}(\%)$} \\
\hline Yes & $22(84.6)$ & $19(82.6)$ & $18(81.8)$ \\
\hline No & $4(15.4)$ & $4(17.4)$ & $4(18.2)$ \\
\hline
\end{tabular}

Group I, at the time of diagnosis; group II, 10-14 days after completion of oncologic treatment; group III, $\geq 2$ years after the treatment.

Table II. Treatment schedules for patients with Hodgkin's disease according to the HD-97 protocol.

\begin{tabular}{lcl}
\hline Clinical stage & Therapeutic group & \multicolumn{1}{c}{${\text { Chemotherapy/radiotherapy }{ }^{\mathrm{b}} \text { sequence }}^{\mathrm{a}}$. } \\
\hline IA, IB & I & B-DOPA/B-DOPA/MVPP/RT \\
IIA & II & B-DOPA/B-DOPA/MVPP/RT/MVPP \\
IIB, IIIA & III & B-DOPA/MVPP/B-DOPA/MVPP/RT1/MVPP/RT2/B-DOPA \\
IIIB, IVA, IVB & IV & B-DOPA/MVPP/B-DOPA/MVPP/B-DOPA/MVPP/RT1/MVPP/RT2/B-DOPA
\end{tabular}

${ }^{a}$ Chemotherapy cycles were administered every 28 days. ${ }^{\text {}}$ Radiation therapy was applied to involved regions (RT) or separately to involved supradiaphragmatic (RT1) and infradiaphragmatic (RT2) regions. Total dose, 15-20 Gy. B-DOPA: bleomycin, 4 mg/m² intravenous (i.v.) days 2 and 5; dacarbazine, $150 \mathrm{mg} / \mathrm{m}^{2}$ i.v. days 1-5; vincristine, $1.5 \mathrm{mg} / \mathrm{m}^{2}$ ( $\mathrm{max}, 2 \mathrm{mg}$ ) i.v.; doxorubicin, $60 \mathrm{mg} / \mathrm{m}^{2}$ i.v. day 1 ; and prednisone, $40 \mathrm{mg} / \mathrm{m}^{2}$ i.v. days $1-5$ per oral (p.o.). MVPP: mechlorethamine (nitrogen mustard), $6 \mathrm{mg} / \mathrm{m}^{2}$ i.v. days 1 and $8 ;$ vincristine, $1.5 \mathrm{mg} / \mathrm{m}^{2}$ (max, $2 \mathrm{mg}$ ) i.v.; procarbazine, $100 \mathrm{mg} / \mathrm{m}^{2}$ p.o. days $1-10$; and prednisone, $40 \mathrm{mg} / \mathrm{m}^{2}$ i.v. days $1-5$ p.o.

the Polish Pediatric Leukemia/Lymphoma Group. Selected immunological parameters of the patients were periodically assessed: At the time of diagnosis (group I), 10-14 days after completion of oncologic treatment (group II) and $\geq 2$ years after the treatment (group III). The profile of the studied population is presented in Table I. Depending on the disease stage (based on the Costwolds modification of the Ann-Arbor classification) (2) and clinical features, the patients were allocated to different therapeutic groups. Table II describes the details of the treatment protocol according to the HD-97 study. The study was approved by the local Bioethical Board.

Assessment of lymphocytes. The percentage and the absolute number of lymphocytes in peripheral blood were assessed on the basis of automatic analysis and microscope examination of blood smears. The evaluation of the lymphocyte subpopulation was implemented by flow cytometry with the use of a Coulter Epics 256 cytometer and System II software by Coulter 
(Beckman Coulter, Miami, FL, USA). Lymphocytes were marked with monoclonal antibodies from Dako (Carpinteria, CA, USA) according to the manufacturer's instructions, following a prior Uti-Lyse erythrocyte lysing. A panel of antibodies against the following antigens were used: CD2/CD19, $\mathrm{CD} 3 / \mathrm{CD} 4 / \mathrm{CD} 8$ and $\mathrm{CD} 3 /\left(\mathrm{CD}_{16}{ }^{+} \mathrm{CD} 56^{+}\right)$. Additionally, in group III the CD45RA and CD45RO antigens were identified. For a negative check, a mixture of isotypic immunoglobulin was used. The lymphocyte population purity was performed with the application of anti-CD45 antibodies (gate-check).

The following lymphocyte phenotypes were analyzed: $\mathrm{CD} 9^{+}$(lymphocytes B), $\mathrm{CD}^{+}$(lymphocytes $\mathrm{T}$ ), $\mathrm{CD}^{+}{ }^{+} \mathrm{CD} 4^{+}$ [T helper lymphocytes (Th)], $\mathrm{CD}^{+} \mathrm{CD}^{+}$(suppressor/cytotoxic lymphocytes) andCD3-(CD16+CD56 ${ }^{+}$(NKcells). Additionally, in group III the expression of CD45RA and CD45RO in T cells was examined (naive and memory cells, respectively).

In all the patients, the concentration of $\operatorname{IgG}, \operatorname{Ig} \mathrm{A}$ and $\operatorname{IgM}$ in blood serum was identified with the application of the immunoturbidimetric method with the appropriate anti-globulin serum by Hydrex company (Warsaw, Poland) with the use of Clinilab equipment. None of the patients underwent a transfusion of immunoglobulin nor plasma concentrates $\geq 4$ weeks before the tests. None of the patients had undergone splenectomy.

In order to compare the results obtained with normal values and to allow them to be independent of age and gender, a $\mathrm{z}$-score was applied. This is the number of standard deviations the individual value differs from the population mean: $\mathrm{z}=(\mathrm{x}-\mathrm{mx}) / \mathrm{SD} ; \mathrm{x}$, examined value; $\mathrm{mx}$, reference population mean; and SD, standard deviation in reference population.

Reference populations were the groups for whom commonly applied age standards were calculated $(3,4)$. A Z-score value was omitted in the case of NK cells, as in the population of healthy people the distribution of the number of these cells does not possess the features of normal distribution $(3,5)$. A comparison between minimum and maximum values, which are considered to be standard, and the average and median values were applied.

The distribution of the $\mathrm{z}$-score value against the reference values was applied, assuming -1.645 and 1.645 values as the minimum and maximum of the normal range. For the normal distribution this corresponds to the 5 to 95 percentile range. Obtained z-score values and the distribution of results in the individual groups were compared by the Kruskal-Wallis test and with the use of $\chi^{2}$ statistics.

Due to the relatively small number of patients in each group, the influence of different therapy schedules were not analyzed, as well as treatment toxicities, however, no major complications of the treatment was observed in the whole studied population.

\section{Results}

Assessment of lymphocytes. The assessment of the absolute number of lymphocytes, percentage distribution and the absolute number of lymphocyte basic subpopulation (excluding NK cells) showed the highest level of irregularities in groups I and II.

In group I, the absolute number of lymphocytes with the majority of children $(19 / 26,73.1 \%)$ remained within the normal limits, whereas they were reduced in six $(23.1 \%)$ and increased in only one case (3.8\%). The percentages and absolute numbers of cells were as follows: Respectively, CD3 ${ }^{+}$ showed lower values at 13/26 (50.0\%) and 12/26 (46.2\%); $\mathrm{CD}^{+} \mathrm{CD}^{+}$at $11 / 26(42.3 \%)$ and $10 / 26(38.5 \%)$; and $\mathrm{CD} 19^{+}$at $18 / 26(69.2 \%)$ and $13 / 26(50.0 \%)$ of the examined patients. For the majority of patients, the percentages and absolute numbers of $\mathrm{CD}^{+} \mathrm{CD}^{+}$cells remained within normal limits at 22/26 $(84.6 \%)$ and $17 / 26(65.4 \%)$, respectively (Table III).

In group II, in $17 / 23(73.9 \%)$ of the children the absolute number of lymphocytes was lower. Lower values were also observed in percentages and absolute numbers of cells as follows: $\mathrm{CD}^{+}$in $17(73.9 \%)$ and $18(78.3 \%)$ of examined patients, $\mathrm{CD}^{+} \mathrm{CD}^{+}$in $22(95.7 \%)$ and $21(91.3 \%)$ of patients and $\mathrm{CD}^{+} \mathrm{CD}^{+}$in $22(95.7 \%)$ and $21(91.3 \%)$ patients, respectively. This group was less clear and more diverse in terms of $\mathrm{CD}^{+} \mathrm{CD}^{+}$and $\mathrm{CD} 19^{+}$cells (Table III).

In group III, the analyzed parameters of the majority of patients did not diverge from the normal ranges. There was a reduced percentage of $\mathrm{CD}^{+}$cells in $6 / 22$ patients $(27.3 \%$ ) only and their absolute value was below the normal standard for two children only $(9.1 \%)$ (Table III). However, $>40 \%$ of the group had a reduced percentage of memory cells for lymphocytes Th $\left(\mathrm{CD}^{+} \mathrm{CD}^{+} / \mathrm{CD} 45 \mathrm{RO}\right)$ (Table IV).

Evaluation of NK cells. The percentages and absolute values of NK cells were reduced in a significant number of patients prior to the beginning of treatment and shortly following its completion, respectively $8 / 26(30.8 \%)$ and $12 / 26(46.2 \%)$ in group I and $4 / 23(17.4 \%)$ and $15 / 23(65.2 \%)$ in group II. However, 2 years after the treatment completion for almost all patients the percentages and absolute values of NK cells were within normal limits, respectively 21/22 (95.5\%) and 20/22 (90.9\%).

Concentration of Ig. The concentration of IgG in group I was notably increased in 13 children (50\%). For the majority of children in groups II and III, the concentration of $\mathrm{IgG}$ remained within age normal limits, but was noticeably lower when compared to group I. The concentrations of $\operatorname{IgA}$ and IgM in the majority of children were not significantly deviated in all the groups, but in groups II and III there was a clear decrease in comparison with group I (Table V).

\section{Discussion}

Malignancies and oncologic treatment are recognized factors that affect the function of the immune system (1). The degree and duration of the disturbance depends on the diagnosis, cytotoxic drugs administered, radiotherapy fields and doses, complications associated with oncologic treatment and adjuvant therapy (blood transfusions, growth factors and intravenous immunoglobulin substitution). To assess the immune defects correctly, repeated examination of patient cohorts treated for the same diagnosis, with the same therapeutic protocol at the same time-points are required. From the practical point of view, these time-points should include the diagnosis and prior to the induction of treatment, the completion of therapy and at least 2 years after the treatment (the suggested time of functional recovery of immune system). In the majority of studies published the results of immune system tests were those that were described at the time of diagnosis 
Table III. Lymphocyte populations presented as z-scores and z-score distribution.

\begin{tabular}{|c|c|c|c|c|c|c|}
\hline \multirow{2}{*}{$\begin{array}{l}\text { Variables } \\
\text { Total lymphocytes }\end{array}$} & \multicolumn{2}{|c|}{ Group I $(n=26)$} & \multicolumn{2}{|c|}{ Group II (n=23) } & \multicolumn{2}{|c|}{ Group III $(n=22)$} \\
\hline & & & & & & \\
\hline Mean & 0.83 & & -1.83 & & -0.15 & \\
\hline Median & 1.37 & & -1.86 & & -0.41 & \\
\hline Range & -2.55 to 6.1 & & -3.2 to -0.12 & & -1.61 to 3.29 & \\
\hline \multicolumn{7}{|l|}{ Z-score, n (\%) } \\
\hline-1.645 to 1.645 & $19(73.1)$ & & $6(26.1)$ & & $21(95.5)$ & \\
\hline$>1.645$ & $1(3.8)$ & & $0(0.0)$ & & $1(4.5)$ & \\
\hline$<-1.645$ & $6(23.1)$ & & $17(73.9)$ & & $0(0.0)$ & \\
\hline $\mathrm{CD}^{+}$ & Percentage & Abs. count & Percentage & Abs. count & Percentage & Abs. count \\
\hline Mean & -1.52 & -1.07 & -3.05 & -2.14 & -0.84 & -0.49 \\
\hline Median & -1.83 & -1.66 & -3.02 & $-2.27^{\mathrm{a}}$ & -0.26 & $-0.57^{\mathrm{a}}$ \\
\hline Range & -4.65 to 1.77 & -2.76 to 5.22 & -7.81 to 1.24 & -3.11 to -0.54 & -4.71 to 1.89 & -1.84 to 1.64 \\
\hline \multicolumn{7}{|l|}{ Z-score, n (\%) } \\
\hline-1.645 to 1.645 & $13(50.0)$ & $12(46.2)$ & $6(26.1)$ & $5(21.7)$ & $15(68.2)$ & $20(90.9)$ \\
\hline$>1.645$ & $1(3.8)$ & $1(3.8)$ & $0(0.0)$ & $0(0.0)$ & $1(4.5)$ & $0(0.0)$ \\
\hline$<-1.645$ & $12(46.2)$ & $13^{\mathrm{b}}(50.0)$ & $17(73.9)$ & $18^{\mathrm{b}}(78.3)$ & $6(27.3)$ & $2(9.1)$ \\
\hline $\mathrm{CD}^{+}{ }^{+} \mathrm{CD} 4^{+}$ & Percentage & Abs. count & Percentage & Abs. count & Percentage & Abs. count \\
\hline Mean & -1.04 & -1.11 & -2.87 & -2.07 & -0.41 & -0.48 \\
\hline Median & -0.85 & -1.55 & -2.95 & $-2.1^{\mathrm{a}}$ & -0.27 & $-0.53^{\mathrm{a}}$ \\
\hline Range & -3.69 to 2.05 & -2.19 to 3.38 & -3.38 to -1.49 & -2.45 to -0.93 & -2.84 to 1.02 & -1.72 to 0.58 \\
\hline \multicolumn{7}{|l|}{ Z-score, n (\%) } \\
\hline-1.645 to 1.645 & $15(57.7)$ & $14(53.8)$ & $1(4.3)$ & $2(8.7)$ & $20(90.9)$ & $21(95.5)$ \\
\hline$>1.645$ & $1(3.8)$ & $1(3.8)$ & $0(0.0)$ & $0(0.0)$ & $0(0.0)$ & $0(0.0)$ \\
\hline$<-1.645$ & $10(38.5)$ & $11^{\mathrm{b}}(42.3)$ & $22(95.7)$ & $21(91.3)$ & $2(9.1)$ & $1(4.5)$ \\
\hline $\mathrm{CD}^{+}{ }^{+} \mathrm{CD} 8^{+}$ & Percentage & Abs. count & Percentage & Abs. count & Percentage & Abs. count \\
\hline Mean & -0.08 & -0.82 & 0.76 & -1.3 & -0.1 & -0.41 \\
\hline Median & -0.13 & -1.32 & -2.95 & -2.1 & -0.22 & $-0.82^{\mathrm{a}}$ \\
\hline Range & -3.05 to 5.33 & -2.25 to 3.23 & -1.71 to 4.87 & -2.39 to 1.18 & -1.81 to 1.97 & -1.7 to 2.22 \\
\hline \multicolumn{7}{|l|}{ Z-score, n (\%) } \\
\hline-1.645 to 1.645 & $22(84.6)$ & $17(65.4)$ & $16(69.6)$ & $12(52.2)$ & $19(86.4)$ & $18(81.8)$ \\
\hline$>1.645$ & $2(7.7)$ & $2(7.7)$ & $6(26.1)$ & $0(0.0)$ & $2(9.1)$ & $2(9.1)$ \\
\hline$<-1.645$ & $2(7.7)$ & $7^{\mathrm{b}}(26.9)$ & $1(4.3)$ & $11^{\mathrm{b}}(47.8)$ & $1(4.5)$ & $2(9.1)$ \\
\hline $\mathrm{CD} 19^{+}$ & Percentage & Abs. count & Percentage & Abs. count & Percentage & Abs. count \\
\hline Mean & -1.28 & -1.77 & 0.04 & -1.53 & 0.07 & -0.33 \\
\hline Median & -1.67 & -1.86 & -0.54 & -1.82 & -0.3 & -0.38 \\
\hline Range & -2.77 to 1.35 & -2.99 to 0.06 & -3.05 to 4.78 & -3.22 to 1.48 & -2.16 to 3.66 & -2.48 to 2.56 \\
\hline \multicolumn{7}{|l|}{ Z-score, n (\%) } \\
\hline-1.645 to 1.645 & $13(50.0)$ & $8(30.8)$ & $5(21.7)$ & $9(39.1)$ & $16(72.7)$ & $16(72.7)$ \\
\hline$>1.645$ & $0(0.0)$ & $0(0.0)$ & $8(34.8)$ & $0(0.0)$ & $3(13.6)$ & $2(9.1)$ \\
\hline$<-1.645$ & $13(50.0)$ & $18^{\mathrm{b}}(69.2)$ & $10(43.5)$ & $14^{\mathrm{b}}(60.9)$ & $3(13.6)$ & $4(18.2)$ \\
\hline
\end{tabular}

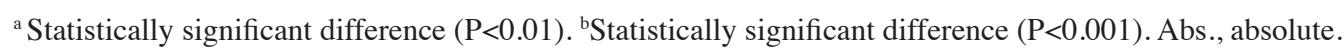

or at various times from the completion of treatment (6-9). Other limitations result from groups of patients that are too small $(10,11)$, different therapy protocols (8) and application of medical procedures that develop secondary immunological disorders, such as splenectomy (9). In the present study, all the patients underwent the same treatment in accordance with the HD-97 protocol, which was based on two chemotherapy courses: B-DOPA and MVPP in a sequence depending on the clinical stage according to the Costwolds modification of the Ann-Arbor classification. Splenectomy was not carried out in any of the cases. All the patients underwent radiotherapy, with mediastinum irradiated in $>80 \%$ of cases. Thus, the presented 
Table IV. Percentage of naive (CD45RA) and memory (CD45RO) cells in group III presented as z-scores.

\begin{tabular}{|c|c|c|c|c|}
\hline Variables & $\begin{array}{l}\mathrm{CD}^{+} \mathrm{CD}^{+} \\
/ \mathrm{CD} 45 \mathrm{RA}\end{array}$ & $\begin{array}{l}\mathrm{CD}^{+} \mathrm{CD}^{+} \\
/ \mathrm{CD} 45 \mathrm{RO}\end{array}$ & $\begin{array}{l}\mathrm{CD}^{+} \mathrm{CD}^{+} \\
/ \mathrm{CD} 45 \mathrm{RA}\end{array}$ & $\begin{array}{l}\mathrm{CD}^{+}{ }^{+} \mathrm{CD} 8^{+} \\
/ \mathrm{CD} 45 \mathrm{RO}\end{array}$ \\
\hline Mean $\pm \mathrm{SD}$ & $-0.26 \pm 1.20$ & $-1.45 \pm 1.05$ & $0.65 \pm 1.13$ & $-0.1 \pm 1.18$ \\
\hline Median & 0.11 & -1.49 & 0.83 & -0.33 \\
\hline Range & -3.0 to 1.64 & -2.97 to 0.37 & -2.64 to 2.54 & -2.0 to 3.06 \\
\hline \multicolumn{5}{|l|}{ Z-score, n (\%) } \\
\hline-1.645 to 1.645 & $20(90.9)$ & $13(59.1)$ & $18(81.8)$ & $19(86.4)$ \\
\hline$>1.645$ & $0(0.0)$ & $0(0.0)$ & $3(13.6)$ & $1(4.5)$ \\
\hline$<-1.645$ & $2(9.1)$ & $9(40.9)$ & $1(4.5)$ & $2(9.1)$ \\
\hline
\end{tabular}

Group III, $\geq 2$ years after the treatment; CD, cluster of differentiation; SD, standard deviation.

Table V. Serum immunoglobulin concentrations as corresponding z-scores.

\begin{tabular}{|c|c|c|c|}
\hline Variables & Group I (n=26) & Group II (n=23) & Group III $(n=22)$ \\
\hline \multicolumn{4}{|l|}{$\mathrm{IgG}$} \\
\hline Mean & 1.59 & -0.53 & 0.46 \\
\hline Median & 1.66 & $-0.51^{\mathrm{b}}$ & $0.39^{\mathrm{a}}$ \\
\hline Range & -1.46 to 4.42 & -2.18 to 1.73 & -1.3 to 3.64 \\
\hline \multicolumn{4}{|l|}{ Z-score, n (\%) } \\
\hline-1.645 to 1.645 & $13(50)$ & $19(82.6)$ & $20(90.9)$ \\
\hline$>1.645$ & $13^{\mathrm{b}}(50)$ & $1(4.3)$ & $2(9.1)$ \\
\hline$<-1.645$ & $0(0.0)$ & $3(13.0)$ & $0(0.0)$ \\
\hline \multicolumn{4}{|l|}{$\operatorname{IgA}$} \\
\hline Mean & 0.31 & -0.75 & -0.55 \\
\hline Median & 0.33 & $-0.69^{a}$ & -0.64 \\
\hline Range & -1.66 to 2.56 & -2.32 to 0.59 & -1.63 to 0.8 \\
\hline \multicolumn{4}{|l|}{ Z-score, n (\%) } \\
\hline-1.645 to 1.645 & $23(88.5)$ & $19(82.6)$ & $22(100)$ \\
\hline$>1.645$ & $2(7.7)$ & $0(0.0)$ & $0(0.0)$ \\
\hline$<-1.645$ & $1(3.8)$ & $4(17.4)$ & $0(0.0)$ \\
\hline \multicolumn{4}{|l|}{$\operatorname{IgM}$} \\
\hline Mean & 0.22 & -1.2 & -0.87 \\
\hline Median & 0.23 & $-1.25^{\mathrm{b}}$ & -1.05 \\
\hline Range & -1.45 to 2.51 & -2.11 to 0.45 & -1.66 to 0.7 \\
\hline \multicolumn{4}{|l|}{ Z-score, n (\%) } \\
\hline-1.645 to 1.645 & $22(84.6)$ & $19(82.6)$ & $21(95.5)$ \\
\hline$>1.645$ & $4(15.4)$ & $0(0.0)$ & $0(0.0)$ \\
\hline$<-1.645$ & $0(0.0)$ & $4(17.4)$ & $1(4.5)$ \\
\hline
\end{tabular}

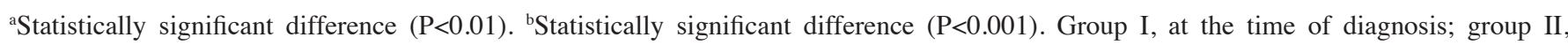
10-14 days after completion of oncologic treatment; group III, $\geq 2$ years after the treatment. Ig, immunoglobulin.

group featured homogenous risk factors of secondary immunological disorders, deriving from the administered oncologic treatment.

Since the majority of immunological parameters show age-related variability, taking into consideration that the age of children diagnosed with cancer varied from 3 to almost 19 years and that the observation time for each patient in the analyzed group was at least 2 years, the results were defined as a z-score value. The exception was the NK cells, as in the healthy population the distribution of the number of these cells does not possess the features of normal distribution (3). HD is a lymphoproliferative disease. Pathognomonic for HD are Reed-Sternberg's cells, which originated from B lymphocytes (1). The abnormality in the number of lymphocytes is 
considered typical for this proliferation $(1,6)$. In the present study, lymphopenia was found in $>20 \%$ of patients at the time of diagnosis, however, in the majority of cases the absolute number of lymphocytes did not deviate from the normal range. In group II, in which the analysis was performed $\sim 2$ weeks after treatment completion, lymphopenia was diagnosed in $>70 \%$ of patients. This is a clear result of the suppression of marrow following the applied chemo- and radiotherapy. In group III, 2 years after treatment completion, the absolute number of lymphocytes was regular for almost all the patients. This data proves that abnormalities in the number of lymphocytes have a secondary character against proliferation and applied treatment, and do not result from any primary immunological deficiency.

Taking into consideration the pathogenesis of the disease, a high irregularity was observed in terms of percentage and absolute numbers of lymphocytes B at the time of HD diagnosis (1). The present study has proved that disorders more often refer to the absolute number (in almost 70\%) compared to relative values (in 50\% of patients). Subsequent to treatment completion, the decrease of the absolute count of lymphocytes B (in almost $61 \%$ of cases) is rather a result of lymphopenia, although in $40 \%$ of patients a reduction in percentage was also observed. Two years after treatment completion the absolute and relative values were within normal limits.

The present study has proved that the disease itself and the applied treatment directly cause deficiencies of $\mathrm{CD}^{+}$and of $\mathrm{CD}^{+} \mathrm{CD}^{+}$cells in particular. However, in the majority of patients these disorders were temporary and in analyses performed $\geq 2$ years after treatment completion, relative and absolute values were normal. The results presented here differ from the data presented in other studies $(1,7,10)$. Different results were also obtained for group III. The percentage of memory and naive cells within $\mathrm{CD} 3^{+} \mathrm{CD} 4^{+}$and $\mathrm{CD} 3^{+} \mathrm{CD} 8^{+}$ subpopulations showed the deficiency of such Th memory cells in $40 \%$ of patients, whereas, Watanabe et al (12) showed a deficiency mainly in naive cells.

Changes within NK cells were less evident and occurred only at the time of diagnosis and shortly following treatment completion. In time-distant tests, they did not diverge from reference values in a large majority of cases. This does not confirm the observation in the study by Macklis et al (9) that radiotherapy of the lymphatic system (large majority of patients underwent such treatment) results in a long-term increase in the population of NK cells. The reason for this discrepancy may be a consequence of complex immunological deficiency in the group presented by Macklis et al (9), as these patients were not only treated with radio and chemotherapy, but also underwent splenectomy.

The present study has proved that the IgA and IgM immunoglobulin concentrations do not change significantly at any of the analyzed stages. Thus, it can be concluded that neither the oncologic disease nor the treatment has a significant influence on the production of $\operatorname{Ig} \mathrm{A}$ and $\operatorname{IgM}$ immunoglobulin. However, the concentration of IgG was higher in half the patients at the time of diagnosis (group I). Similar observations have been reported in the study by Tan et al (13). Considering the fact that in almost all the patients immediately following treatment completion, and in further examinations, the concentration of this immunoglobulin is correct. Therefore, it could be concluded that intensified production of $\operatorname{IgG}$ is associated with immunological disorders that are caused by the oncologic disease itself.

Results of the present study show a prolonged immune defect in certain patients, which may lead to increased susceptibility to infections. This justifies the importance of preventive immunization following completion of oncologic treatment. Numerous vaccination guidelines are available, however, the timing, vaccine doses and their efficacy remains under development (14-16).

In conclusion, disorders in the percentage distribution and individual subpopulations of lymphocytes applied to patients mainly at the time of the diagnosis and immediately following completion of treatment. Therefore, the disorder is a result of the pathogenesis of the disease and of the influence of oncologic treatment. Also, the analysis of time-distant consequences showed only deficiency of memory Th lymphocytes. Additionally, the concentration of $\mathrm{IgG}$ at the time of diagnosis was significantly elevated in half the patients, which is possibly associated with the pathogenesis of the disease. The treatment does not appear to noticeably affect the production of $\operatorname{IgG}, \operatorname{Ig} \mathrm{A}$ and $\operatorname{IgM}$, although their concentrations were lower following the completion of therapy in comparison to the diagnosis.

\section{References}

1. Dayer-Pastore F, McClain KL and Shearer WT: Secondary immunodeficiencies due to proliferative and histiocytic disorders. In: Immunologic Disorders in Infants and Children. Stiehm ER, Ochs HD and Winkelstein JA (eds). 5th edition. W.B. Saunders, Philadelphia, PA, pp835-857, 2004.

2. Olweny CL: Cotswolds modification of the Ann Arbor staging system for Hodgkin's disease. J Clin Oncol 8: 1598, 1990.

3. Comans-Bitter WM, de Groot R, van den Beemd R, et al: Immunophenotyping of blood lymphocytes in childhood. Reference values for lymphocyte subpopulations. J Pediatr 130: 388-393, 1997.

4. Zeman K, Fornalczyk-Wachowska E, Pokoca L, et al: Percentual composition of basic lymphocyte subpopulations and NK cells in Polish popoulation. Cent Europ J Immunol 21 (Suppl 2): 107-113, 1996 (In Polish).

5. Grześk E, Kołtan S, Dębski R, et al: Concentrations of IL-15, IL-18, IFN- $\gamma$ and activity of $\mathrm{CD}^{+}, \mathrm{CD}^{+}$and NK cells at admission in children with viral bronchiolitis. Exp Ther Med 1: 873-877, 2010.

6. Dębski R, Wysocki M, Kołtan S, et al: An assessment of lymphocyte B, T and NK subsets in peripheral blood and serum immunoglobulin concentrations in children with acute lymphoblastic leukemia and Hodgkin's disease at diagnosis. Pediatr Pol 80: 354-359, 2005.

7. Dębski R, Wysocki M, Kurylak A, et al: Evaluation of lymphocyte B, T and NK subsets in peripheral blood and serum immunoglobulin concentrations in children with acute lymphoblastic leukemia and Hodgkin's disease after oncological treatment. Przeg Pediatr 35: 131-136, 2005 (In Polish).

8. Eckschlager T, Průsa R, Hladíková M, et al: Lymphocyte subpopulations and immunoglobulin levels in Hodgkin's disease survivors. Neoplasma 51: 261-264, 2004.

9. Macklis RM, Mauch PM, Burakoff SJ and Smith BR: Lymphoid irradiation results in long-term increases in natural killer cells in patients treated for Hodgkin's disease. Cancer 69: 778-783, 1992.

10. Alanko S, Pelliniemi TT and Salmi TT: Recovery of blood lymphocytes and serum immunoglobulins after treatment of solid tumors in children. Pediatr Hematol Oncol 11: 33-45, 1994.

11. van Tilburg $\mathrm{CM}$, van Gent $\mathrm{R}$, Bierings $\mathrm{MB}$, et al: Immune reconstitution in children following chemotherapy for haematological malignancies: a long-term follow-up. Br J Haematol 152: 201-210, 2011.

12. Watanabe N, De Rosa SC, Cmelak A, et al: Long-term depletion of naive $\mathrm{T}$ cells in patients treated for Hodgkin's disease. Blood 90: 3662-3672, 1997. 
13. Tan CT, De Sousa M and Good RA: Distinguishing features of the immunology of Hodgkin's disease in children. Cancer Treat Rep 66: 969-975, 1982.

14. Bernatowska E: Prophylaxis of infectious diseases in immune deficiencies. Standardy Medyczne 34: 4-42, 2008 (In Polish).

15. Kołtan S, Kołtan A, Grześk E, et al: Analysis of the immunological reconstitution, effectiveness and safety of vaccination in children with cancer. Przegl Epidemiol 64: 537-542, 2010 (In Polish).
16. Rubin LG, Levin MJ, Ljungman P, et al: 2013 IDSA clinical practice guideline for vaccination of the immunocompromised host. Clin Infect Dis 58: e44-e100, 